\title{
Establishing knowledge gap issues in Kenya: Why information for innovation on digital television is difficult to access among Jua Kali artisans.
}

\author{
Martin Kuria \& Erneo Nyakundi Nyamboga
}

\begin{abstract}
The Kenyan engineering artisans a.k.a ' jua kali'( hot sun) engineering artisans, do not easily and readily find information for innovation in the digital television platform. The researchers, therefore, sought to establish whether engineering content shown in the Kenya digital platform inspires creativity for innovation among this category of engineering artisans who mainly operate from open air spaces and under the hot sun. The study was anchored on the pragmatic research philosophy. The study employed a mixed methods approach and a multiple case study research method. A sample of 60 participants, comprising artisans and media content producers, was studied.The findings showed that $67.9 \%$ of the engineering artisans had considered that there is interesting and available innovation content in the digital television platforms. However, there were attitudes that hindered accessibility of useful innovation information from the digital television gadgets. Media producers cited that they had not fully grasped how the digital platform can work. It is hoped that these findings will encourage the production of interesting, innovative content, that will give rise to alternative information sources for engineering artisans.
\end{abstract}

Key words :- Engineering artisans, media producers, Kenya, innovation, digital television, knowledge gap, mixed research.

\section{INTRODUCTION}

To innovate is to think differently, it is creating new things, ideas, concepts, developments, improvements and ways of doing things to obtain strategic advantages (Ali, Ullah, \& Khan, 2007). However, innovation cannot occur in the absence of acquiring knowledge on existing inventions (Khan, Ullah, \& Murah, 2009). The Jua Kali artisans or blue collar workers in Kenya are considered to be the key product innovators in the informal sector, so sufficient knowledge acquisition is a key prerequisite for their survival. Information is a resource. It has value and it lets people do things that they could not do otherwise. It is apparent that knowledge is not distributed equally throughout society. People who are in financial poverty, such as Jua kali engineering artisans are also often information poor. An unexpected and undesired possibility is that mass communication might actually have the effect of increasing the difference or gap in knowledge between members of different social classes Severin \& Tankerd (2001). For the Kenyan case, this study focuses on engineering blue collar artisans who work under the hot sun, also referred to as Jua Kali engineering artisans.Jua Kali artisans are affected by issues knowledge accessibility. Most of them are from a low economic background and are unable to innovate. This research takes stock of the conditions Jua kali artisans are facing to enable them to acquire access to innovation information.

\section{LITERATURE REVIEW}

Research literature by Patterson, Kerrin, \& Gatto-Roissard, (2009) bring to the fore, that an intense involvement in domain specific knowledge is a pre- requisite for innovation. Domain -relevant knowledge reflects how much an individual knows about a given area. The knowledge does not need to be highly complex or detailed and it can be broad (Patterson, Kerrin, \& Gatto-Roissard, 2009). It is therefore in order to suggest that the digital television platform can create a media system that Jua Kali artisans can learn from and acquire domain relevant knowledge, useful for innovation.It is likely that when one looks at the Kenyan Jua Kali artisans, one sees people with a lot of potential. One may wonder loudly why they seem not to make much headway even as they try their hands on various products. They appear to be doing things the same old way, sometimes in ways that have been tried elsewhere in the developed world and failed. Wangare (2015) suggests that the reason could be that Jua Kali artisans apply reverse engineering and trial and error as the primary knowledge creation activities in the sector. Perhaps this is why they don't seem to make much headway in innovation. Many other Kenyans share this outlook. An example is Micheni (2007) who observes that most Jua Kali artisans live in Nairobi area and they trek to their sheds to tackle what has become routine Jobs. Lack of novelty has derailed the promising Jua Kali sector. 
Again Ndemo (2014) mentions that the sector of Jua Kali is characterized by poor infrastructure, lack of financial resources, poor production capacity, low levels of health and safety standards, low awareness of environmental issues, little or scarce information that is essential for technology transfer and dependence on large industries for the supply of raw materials. Subsequently, it would be essential to emphasize that the informal contacts with these Jua Kali artisans bring to the fore, a lack of innovation information, and inability to access information that would make their products and services better.

It is noticeable that innovation information on past strides in existence is not easily and readily available to the Jua Kali artisans in Kenya, especially through the media. This is as expressed by Kibe (2016) who conducted a study on knowledge sharing techniques amongst Jua Kali artisans in Kenya. The researcher found that most of the Jua Kali artisans use mentoring as a way of sharing knowledge. These knowledge sharing techniques were hampered by a language barrier largely because trainees and trainers mostly communicate in their vernacular (Kibe, 2016). This could mean that if digital television platform would be adopted, it would be a necessary tool, because they can apply vernacular as a mode of communication in knowledge sharing.

Additionally, one expects that innovation information will be in a medium or form that Jua Kali artisans can comfortably consume however this is not the case. Consequently the scanty Innovation information out there in the media on past endeavors is in areas other than what the Kenyan Jua Kali engineering artisans are engaged in. This is as depicted by Wangare (2015) who conducted a study on knowledge management in the informal sector. A review of Kenya's Jua Kali industry. Wangare (2015) concludes that there are informal knowledge management practices among the Jua Kali. Results suggested that Jua Kali mediums for information included exhibitions, workshops and seminars that typify channels through which new ideas are disseminated to Jua Kali artisans.

Knowledge sharing is characterized by drawing sketches and modeling, while Knowledge preservation is largely defined by photography. Knowledge retention and protection were however found to be uncharacteristic of the Jua Kali sector (Wangare, 2015). It is evident that low media usage in knowledge management could be a factor that affects Jua Kali artisan's ability to access relevant information for innovation. If the media was used accurately, It could change how Jua Kali artisans retain and protect knowledge. The researcher therefore feels that Jua Kali artisans would be at the high end of innovation, if content on past prosperous and failed endeavors was available to them in the form they can easily understand and preferably through a medium of choice.

Media producers were pivotal in this study in explaining how the digital television platform can be adopted as the media of choice among Jua Kali artisans. UNESCO (2016), has regarded the media as part of a useful tool in meeting the sustainable development goal of using platforms, such as the media, that offer a forum for accessing creative and innovative productions for development, especially for populations like the Jua Kali artisans.

UNESCO, (2016) cites that media producers are pivotal in understanding the issues of content production and distribution. They will assist in promoting understanding between populations. Further media producers are also decision makers who could be broadcasters in developing countries public or commercial broadcast companies that rarely purchase the broadcasting rights of the content made locally.

Additionally UNESCO is sensitizing the decision makers and the public at large about the importance of local content in the promotion of cultural diversity and facilitating alternative communication channels and showcasing local productions at the local and international level (UNESCO, 2016). Therefore, in this research, media producers will be pivotal in explaining how content could be availed to engineering Jua Kali artisans, who are seen as potential local innovators that encourage the countries' development.

\section{RESEARCH METHODOLOGY}

This research adopted the pragmatist research paradigm. Pragmatists view knowledge and the world generally as being both realist and relativist (Robson 2002) Consistent with this paradigm, the research approach is mixed methods. Subsequently the approach was carried out in accordance with the multiple case study method, as explained later in this chapter. In line with the pragmatist philosophy, the ontological position which is about the nature of reality is that reality is constantly renegotiated, debated and interpreted in light of its usefulness in new unpredictable situations. There are different ontological perspectives on the nature of reality. Subsequently, in line with the pragmatist philosophy, the epistemological belief which is about the best method to use to study the reality is that the best method is the one that solves the problems. Finding out the problem and solution is the underlying aim. As explained earlier a mixed research approach was employed in this study. This is where both qualitative and quantitative data are used to give an all rounded perspective of the phenomenon being studied (Johnson and Christensen, 2008; Saunders, Philip and Adrian, 2007; Johnson and Onwuegbuzie, 2004). There are different strains of mixed methods. Creswell (2009) discusses about the sequential and concurrent approaches. This study was anchored on the sequential explanatory strain of mixed approach. The mixed research approach was selected for its value in research as described by Creswell and 
Clark (2007, pp. 9-10), It provides strengths that offset the weaknesses of both quantitative and qualitative research.

The research method used in this study was a multiple case study. It is a process of research in which detailed consideration is given to the development of a particular person, group, or situation over a period of time. A case study to begin with may include a single person, a group of people, an organization or an institution. Some case study research may involve the research of a series of cases or more than a single case. In this study, the researcher looks into more than one case, that is the issue of Jua Kali engineering artisans as audiences and media producers for cross validation making it a multiple case study. It is more like doing multiple investigations (Robson, 2002).This study was carried out in Nairobi, Kenya; it was focused on two political sub counties which are Makadara and Kamukunji. Nairobi is a metropolitan city. It is home to many people who have migrated from the rural to the urban areas in search of employment. The majority of these people who cannot find formal employment find it in the informal sector, which is what is called Jua Kali meaning the hot sun. The study population includes media producers who have at least produced a show and engineering Jua Kali artisans in Kenya.The quantitative phase of the mixed method involved Multistage sampling, it represents a more complicated form of cluster sampling in which larger clusters are further subdivided into smaller, more targeted groupings for the purposes of surveying. To that regard Purposive sampling was applied to choose two administrative constituencies, because of the proximity and availability of data based on the premise that Juakali artisans are more in these counties. Then proportionate stratified sampling was applied to establish the number of engineering Jua Kali artisans in each of the 17 sub-counties in Nairobi County. Kenya has a population of 4.1 million Jua Kali artisan (ILO, 2001). There are about 19 varieties of Juakali artisan (King, 1975) classification. Assuming an equal distribution of artisan per Jua Kali category each would be expected to have 215,289, so it was projected that Kenya has 215,289 Jua Kali engineering artisans. Kenya has 47 counties, so Nairobi County would have 4,393 engineering Jua Kali artisans. Nairobi County is also projected to have 17 political sub counties or constituencies - Westlands, Dagoretti North, Dagoretti, Langata, Libra, Roysambu, Kasarani, Ruaraka, Embakasi South, Embakasi North, Embakasi Central, Embakasi East, Makadara, Kamkunji, Starehe and Mathare. Each sub- county or constituency would be projected to have 258 engineering Jua Kali artisan. A sample of $10 \%$ of each sub-county would be approximately 31 engineering Jua Kali artisans and these are representative of 258 engineering Jua Kali artisans per sub-county. Therefore a total sample of 60 engineering Jua Kali artisans were tested at, this was a representative sample of 516 engineering Jua Kali artisans from two sub counties. They were again randomly selected against five engineering categories used to select the Jua Kali artisans in the different categories. These engineering categories were sound, mechanical, electrical, automotive, and machine engineering. The sampling procedure for the qualitative phase of the mixed method was the use of snowballing to select five engineering Jua Kali artisans. While purposive sampling was used to select media producers who had at least produced a show. Snow balling sampling technique works like a chain referral. After observing the initial subject, the researcher asks for assistance from the subject to help identify people with a similar trait of interest. The chain referral process allows the researcher to reach populations that are difficult to sample when using other sampling methods. The data generation procedures involved the use of research instruments which included a questionnaire with a list of Likert scale type question and semi structured interviews were conducted through the use of interview schedules. Questionnaires were administered to the Jua Kali artisans. Both media producers and Jua Kali artisans were taken through informant interviews that were semi structured. According to Johnson and Christensen (2008) an interview is quite popular because it is free from bias and respondents have adequate time to give well thought out answers (Johnson and Christensen, 2008).

A pilot study was conducted in this study. One sub County Embakasi South was involved in the pilot phase where Jua Kali mechanical engineers were administered with questionnaires. Deliberate efforts were made to exclude the county involved in the pre-test during the actual research. The piloting of instruments was tried out on a small group similar to the one that formed the population of the study, a view supported by Bell (2005). The pilot involved 15 Jua Kali mechanical engineering artisans. According to Gay et al. (2009), three or four participants of the intended research participants should complete the questionnaire before actual research for a survey. In the same light Yin (2009) contends that, a pilot case study should be conducted. The criterion for the pilot study was to consider the convenience, accessibility and geographical proximity. The need for piloting was to check the relevance and establish whether the instruments will adequately generate the required information, contain the proper wording of questions, proper language use, the arrangement of the items, rule out any repetitions and redundancies, ensure the data collected would be analyzable and whether the questions are acceptable, how much time would be needed in each industry and enhance the validity and reliability of the itemsIt is believed that using different types of procedures for collecting data and obtaining that information through different sources (media producers and Jua Kali artisans, etc.) Can augment the validity and reliability of the data and their interpretation (Zohrabi 2013). In order to ensure high response rate, the questionnaires were administered by either the researcher or a trained research assistant this ensured high reliability and return rates. 
The schedule interviews on the other hand involved asking semi structured questions, where the researcher was the interviewer. A research assistant was involved in note taking and recording using an electronic recording device to ensure that the interviewer maintained concentration in engaging the interviewees. Data saturation was reached when there was enough information to replicate the study, when the ability to obtain additional new information had been attained, and when further probing was no longer feasible. The use of the two methods of data collection encouraged data saturation which could be attained in a number of methods (Denzin, 2009, 2012).

The data analysis for this study was a mixed analysis since it was guided by a mixed approach. Mixed data analysis means both quantitative and qualitative analytical techniques are used in a single research study (Johnson and Christensen, 2008). A similar explanation is also given by Creswell (2009) that analysis occurs both within the quantitative (descriptive and inferential numeric analysis) and the qualitative (description and thematic text or image analysis) approach and often between the two approaches. The analysis was an interactive process along themes created from both the quantitative and qualitative data. The ethical issues observed in this paper are

Response Rate

The target sample was 62 in the two administrative constituencies; however a final sample of 53 respondents was realized which comprised a response rate of $88.3 \%$. The response rate is acceptable according to Hamilton (2003) who explains that a rate of $50 \%$ is appropriate in guaranteeing accuracy and minimizing bias, a $60 \%$ response rate is adequate or better and a $70 \%$ and over response rate is very good. In this case, the sample response rate was at $88 \%$. Well over the $70 \%$ standard. This implies that the response rate was very good for the survey. It was also established that $75.4 \%$ of the respondents had the most access to just a TV, CD player, DVD player, mobile phone, a mobile phone with internet and TV with set top box. $7.5 \%$ of the respondents had the most access to just a DVD player, television and a mobile phone. Further, 17.0\% were able to have the most access with just a DVD player, TV set with box, computer with internet, and mobile phone with internet. These findings indicate that a majority of the Jua Kali artisans can benefit from the digital television platform if correct applications and changes are made. Equally, the majority of Jua Kali producers have the possibility of being innovative because they have access to a TV, CD and DVD player, Mobile phone with internet and Set top box. Therefore, they can incorporate content which will be nature innovation hence, this dispels the belief that Jua Kali artisans may not be able to afford devices of the digital television platform due to financial constraints.

The researcher also found that $67.9 \%$ of the respondents had considered that there is available content that could be useful in applying to their work. $9.4 \%$ were neutral and only $22.6 \%$ of them had never considered whether there is available content that could be useful in applying to their work. The implication could be that there is a great understanding that there is content that could be available. This could mean that with sensitization and a proper structure, the digital television platform can be made gratifying with content that is not only available but accessible.In the semi structured- interviews with a Jua Kali artisan, concerning what they understood about the digital television and whether there is available content in the first place, it was noted that the understanding of digital television platform was varied. In fact, the most prominent perspective was that the digital television platform is about the internet while others thought it was all about offering a clear signal to television viewers. However, it was not viewed as a tool of educating or informing oneself. Nonetheless, it was mentioned that respondents understood that it could be used as a reference tool for Jua Kali artisans since content is available. This was as shown by Jua Kali engineer respondents MO1 and S01 who stated that

M01: The digital television platform as I understand it is about making television extremely clear, the pictures are better and clear, it is no longer about sharing Ariel signals and fighting with your neighbors. But quite honestly in my experience, I find the internet alone as most useful. I get onto the internet every day because of the work I do. I can get illustration diagrams of the sound systems such as the one that are here and find out what their common issues are, and how solutions can be found for them. I find everything about my work by checking from the internet.

Respondent S01 also added

S01: I have never quite understood this digital television concept at all. But I can tell you more about my phone...

Subsequently the findings from some of the respondents also indicate that they are aware of YouTube channel as a source of videos that can assist with reference. It comes with to do it yourself techniques that can assist one to fix and make equipment work better. It therefore seems that the use of the internet is seen more useful in finding suitable visual content. However, television, which is also called the single screen in the family home is not considered as a learning tool neither is it viewed to have interesting content. It also seems the digital television platform is also observed to be a fairly new concept where people do not consider or believe that they can watch videos or access content that is innovative whenever they want through mobile gadgets. Again, this is because they don't fully understand how the digital concept of innovation works. So they do not gratify their 
needs with tools that the digital television platform offers. Furthermore, some respondents reported to have used the platform to innovate, however, they admitted that the concept is still new. It is clear to them that the digital television platform as a tool can bridge the gap between those who are self-taught and those who are not able to go to tertiary institutions to learn the different engineering trades. It was also established that the biggest hindrance to the use of the digital television platform as a reference tool to nurture innovation was ignorance. This was as depicted by Jua Kali engineer E03 who stated that: E03: If you mention the broad term digital TV; I can say they are helping because they encourage internet use. At times you can get something that needs fixing and it gives you a challenge. At times, the programs on the internet, you tube videos come with to do it yourself techniques that can assist one to fix and even make something work better. But few Jua Kali engineers understand how to use these tools, either out of fear or out of ignorance. Usually when there is new equipment such as new radios or television sets in the market and I have never seen them before, what I usually do is Google the product number and then I key in the problem to the computer where the product's company website lies. I then find that those companies have ready video links that assist you to see how various problems are solved. At other times, you tube becomes useful in sorting out these issues that are seen to be common and experienced by many people. However, mostly we conduct such work on the internet. Television does not give us such opportunities. At times the information even on the internet in terms of the videos is so rare that you only get it in text formats such as manuals.

Additionally, set box televisions were not viewed as useful due to the fact that content available was difficult to access. This is because ones' choices are limited as compared with the internet. When respondents were asked in an interview about what was observed, it was felt that respondents felt traditional TV does not show useful content. It was also found that Jua Kali artisans still find it difficult to use the concept of internet at work, especially on a mobile phone and that it is only with the internet, that people are likely to get work related videos that matter. It also emerged that issue of accessing content was imminent. Various respondents who were interviewed pointed out that perhaps, programs could be scheduled on certain days of the week on the set top box form of television.

S01 stated: There is nothing in terms of programs concerning my work that I see being brought on TV that is useful. But I can confidently say that on the phone or in the internet I believe I would find some useful things that I can follow from my mobile phone. On the phone, I can Google, but the problem with Google or the use of Google is that I find it difficult to use.

Question three was answered by trying to investigate whether Jua Kali artisans had ever found videos that were contributing to the work they do in captivating ways. Item 8 of the questionnaire evaluated this by finding out whether the videos were captivating and in existence.On the matter of finding captivating content $71.7 \%$ of the respondents agreed that there were videos that could be watched on the digital television devices that can tell them what to do in interesting and captivating ways. $11.3 \%$ were neutral while $16.9 \%$ of the respondents disagreed on whether they can look at digital television devices for videos that can tell them what to do in interesting and captivating ways. These findings mean that a majority of the respondents feel that captivating content can be found and that it does exist. This also answers the question that the digital television platform has captivating interesting content. The face to face finding from an interview further validate the view that engineering Jua Kali respondents found content that was told in captivating way regarding the work they do. This is what one of them said:

MO2: I can attest that the internet has a lot of content, for instance, let's say I have gone to Kenya Polytechnic, my literacy is better and there are those whose literacy is low, such people need some form of assistance. There is a need to make such content more accessible. It would be amazing if people can find content in vernacular, in a way, what discourages people in my perspective is ignorance, for instance, today if you want a phone and a good one they are cheap and accessible now. If it is computers, we have cyber cafes everywhere that allow you to have access to videos or texts and helps you talk with manufacturers through their interactive websites. Many homes now have at least a desktop. But I must say people need an attitude that encourages pro- activeness. Right now companies like Safaricom are even in the rural areas and now even villagers have access to the internet. Therefore, this are things that people need to be encouraged more to use. Another respondent E03 suggests that it is possible for engineering Jua Kali artisans to call the internet a tool of work. The content on the internet is-interesting and current. The respondent reminisces that he left college a long time ago and there are elements of his work that he learned on the job, this shows that the digital television platform is clearly forming a different role; that of training people on how to do their job and creating structures and curriculum in the sector of informal education. It is clear that there are many tutorials that can help in the understanding of technologies and how to innovate. It is against this background that it can be said that there is interesting and captivating content.

E03 stated that:

I get onto the internet every day because of the work we do. Because you know technology changes every day, and what we learn in college is sometimes not what we practice. The content is interesting and is 
current. We were not also taught everything in college, for instance a person like me, I finished college twenty years back. And at that time, things like phones or fixing of phones I was not taught because they were not part and parcel of our day to day living. But now you can find very many tutorials from the internet that are both interesting and captivating and are helping our understanding of technologies and how to innovate. The researcher tried to find out from the perspective of media producers what interesting content is available and perhaps the formats that are taking shape and are increasingly being used to create interesting content: The findings from some of the media producers, indicated that there is interesting content and the genre of television which is reality television is capturing audiences, and creating interest among engineering Jua Kali artisans. This program is aimed at promoting innovation and it is shown mostly on pay television or pay per view internet sites.It was suggested that reality television is the best trend right now, to create content for blue collar workers. The idea behind reality television is that it is cheap to produce, and stories are catchy and interesting to follow. It can depict real life settings of characters whom Jua Kali artisans can relate to. Another way that can act as an easy to access form of content, are the do it yourself videos and they lie in the digital television platform. This was as suggested by Media Producer respondent E01 below who seems to understand that Jua Kali engineers probably get solutions from amongst themselves. So there is a need to give motivation that the content should be easily accessed. These concepts, however, may require bigger equipment and bigger crews. The idea then is that the concept of digital television means that people have to see that there are more opportunities from all the different genres targeting all these different audiences such as hair stylists, chefs and mechanics.

E01: Reality television is the way to go. It is being adopted as a great avenue to make the biggest productions that are cheap, it is cheap, it is affordable, it is quick to produce, and the stories are catchy and interesting to follow. For instance on the quest channel we have reality shows on making Harley Davidson chopper bikes where the real lives of Jua Kali like people are shown without a script as they build hot rod motor bikes. Another thing that we can say is really catchy are the do it yourself videos. We cannot compare the two types of production because reality genre videos are more complex as compared to do it yourself video. Again Jua Kali artisans are not people that would want to study two years doing something. The tactics employed in reality television seem to refer to the techniques of production where content is considered entertaining if it has humor, music and drama. Again, all these again are elements found in a reality television show. It was also felt that already there are programs that are incorporating these elements and they are selling outside and within the country. The elements are concepts that are not just entertaining, but people identify with them. These elements are used to help predict where the market is going and how audiences can be hooked. These issues are as depicted by respondent R02 on a similar issue also observed that:R02: I will never exhaust tactics from the concepts of entertainment, humor, music, drama, you will never ever have less content on that and these are areas that can be borrowed and are in existence to create innovative content that is enjoyable and realistic and that is what is selling out there. That is the only thing I can tell you in understanding how to create interesting content. We already see this, we have content with a mix of humor, music, drama and realistic perspectives and this is what brings interest because it is a day to day thing. The music that comes out is what people identify with. You see what is becoming trendy is what is telling you what is trending and it can give you an understanding of where you want your market to go and how to hook audiences. However, we are yet to apply this for Jua Kali artisans. Shamba shape up is considered entertaining, even humorous at times. So this could be a good example.

\subsection{The discussion on finding interesting content to be found on the digital television platform}

Electronic media are known to touch virtually all facets of human beings' lives. They are persuasive as they provide us with the messages that influence us in many ways (Medoff and Kaye, 2010; Oliver, 2014)). This view is supported by (Thioune, 2003; Adam, Butcher, Sibthorpe and Tusubira 2010), who argue that ICT plays a major role in all aspects of life - in politics, economic life, as well as in social and cultural development. This is because ICT is rapidly transforming the way people do business, access information, give services, communicate with each other and even spend their leisure time.

Another notable argument to this effect is that ICT is a principal driver of economic development and social changes worldwide and one of the basic building blocks of modern society (Kozma, 2005; Leach, 2008; UNESCO, 2002). It has provided the impetus for economic innovation, cultural revolution and social reform in the health and education sectors (Kidd, 2007; Van, 2007; UNCTAD, 2011). Gasco (2006) further explains that technology has speeded up the progress of humanity while Selwyn (2011) posits that the use of digital technology is considered the simple priority of keeping up with the changing trends. The findings of the study so far seem to agree with Quail's (2012) article on television going online: Myths and realities in the contemporary context. They give a picture as of how the entire globe is dealing with the issues of digital media use. Quail's 2012 article has highlighted some issues in the Canadian context and globally. Quail suggests that there is an 
inaccurate representation of internet use. In fact, it could be that Africa is now accessing more internet and more content than before. This then disqualifies the idea that Jua Kali artisans cannot access internet.

The digital divide similarly could be applied to each country's Internet access and computer ownership, which are closely tied to income, wealth of the country, social status, educational and skill level as well as age. This proves to create a multi-tiered global divide of users, perhaps best understood through the "hype" and "obsession" model, as demonstrated by Schuurmanetals (2009) and discussions of Gartners Hype Cycle theory, based on Rogers diffusion of innovation approach. In this model, technology follows along a "peak of inflated expectations, slope of enlightenment and the plateau of productivity necessary to be a profitable innovation" ( $p$. 294). They argue that the world may still be witnessing the peak of inflated expectations of online viewing, hyped and obsessed over by small, yet influential, portions of the population.

Internet access itself cannot be equated to watching TV online, or the potential to download, nor can it be in actual downloading practices in various countries (Quail, 2012). Therefore The findings of the study can then be supported by Qual (2012), because it was found that many Jua Kali artisans understand the need to use the internet and even have electronic gadgets to access it. However, they still faced challenges, among them attitude issues and accessibility. This rationale is verified by findings that a majority of the engineering Jua Kali artisans can access at least a mobile phone with internet, a television set top box, DVD and CDs. This could mean that Jua Kali artisans who find access to content difficult would be in this state because of an inability and ignorance of how to use the internet or it could be an attitude problem that the internet is far too difficult to use. It could also be because the internet and digital set box services are considered expensive and the preserve of the few privileged people in society who may be from certain backgrounds, age or social orientation. Further, it could be because digital television from set top boxes gives us limited choices in getting desired content, since content is still very much generalized to a wide audience and not characterized by the various niche audiences that are reflected in the society and is also considered expensive.

Additionallly, digital content was-found to be difficult to access among Jua Kali artisans. It is only a few who manage to use it to innovate. One of the ways the media can be made more accessible and more interesting is by the development of electronic program guides and recommendation systems which Soares and Viana, (2014) raise. These will encourage people to access content with ease. The expansion of Digital Television and the convergence between conventional broadcasting and television over IP has contributed to the gradual increase of the number of available channels and on demand video content. Moreover, the distribution of the use of mobile devices like laptops, smartphones and tablets on everyday activities has resulted in a paradigm shift from the traditional television coach viewing to everywhere, anytime from any device (Soares \& Viana, 2014). Although this new scenario enables a great improvement in viewing experiences, it also brings new challenges given the overload of information that the viewer faces. Recommendation systems stand out as a possible solution to help a viewer on the selection of the content that best fits his/her preferences (Soares \& Viana, 2014). It is through recommendation systems that television can be made easy to access for Jua Kali artisans who know there is content but find it difficult to access.

Another probable way that content can be made interesting is by the factoring of reality television genre formats. Dyer (2010) discusses that since the beginning of the $21^{\text {st }}$ century, reality TV had begun to monopolize both cable and broadcast prime time television programming schedules. In this context, reality TV is defined as a show without actors in which the general public has access to becoming a contestant on the program. What those in television business can understand is that reality TV is the most profitable form of television programs because it has lower production costs and often brings in more viewers and more advertising revenue than scripted programs (Hirschorn 2007). It is therefore possible to say that local Kenyan broadcasting stations can find it more profitable to adopt this genre for niche audiences such as the Jua Kali artisans because of low production costs that can bring in more viewers and niche advertisers.

It is easier to understand why the networks are producing reality TV, Programming has become much more interactive for viewers because they can literally become a part of the show by being contestants on a reality TV show, or they are often able to watch the program and vote on the fate of other contestants on the show. Viewers must also remember that the participation in these shows is seemingly voluntary, thus challenging the fact that participation in these programmes could be exploitative.

Nonetheless, while participation is voluntary, programs have a motive behind the casting of reality TV programs. In efforts to gain the largest and most diverse demographic, casting is methodical. "Most TV shows want us to see ourselves on screen" (Berman, 1987, p. 103) so in order to appeal to the masses, conscious efforts are made to have many different types of people within a show so that viewers can find someone with whom they may closely relate with. Not only do these new programs open doors to deeper para-social relationships, but they also allow for a more interactive viewing experience for the audience through new media platforms, which may be a key idea as to why audiences are choosing to engage in and watch these programs. 
The findings of this study are highly supported by various authors. Wambaria (2015); Fullerton, Berry, Seels, and Horn (2005) who evaluate the concept of the knowledge based economy. They agree that television can be used for instruction and learning, however, it requires policy that will control advertising, the provision of special programming and media literacy education. Roscoe (2004) also adds that the proliferation and success of popular factual formats, the process of digitization and the emergence of interactive technologies have transformed the global television landscape. Content is now being produced, delivered and consumed in new ways. Capitalizing on these changes are a set of complex multi-platform media events that deliver a range of content across various platforms, utilizing television, the Internet, mobile phones, and digital and interactive screen services. Wambaria (2015) goes a step further to explain that ICTs may be used to improve efficiency in education, administration and management. It is clear that ICTS can be used for learning, hence engineering artisans who have the most access to the electronic communication that is digital in nature have more access to content and with sensitization they can acquire new tools to learn and innovate.

The face to face findings from the semi structured- interviews with Jua Kali artisans revealed that, Jua Kali artisans had not quite understood the use of the digital television platform. This could have an effect on their use of the platform. The findings also revealed that conventional television did not bring about the necessary content that can lead to nurturing innovation. It was felt that if the respondents took more time with the internet, there is likelihood that the respondents will be able to find the content needed since internet is now considered a part of digital television. This then provides the reason why Jua Kali artisans are unable to become innovative from the digital television platform. They find gratification from the various mediums of digital television platform. In finding what they expect, they can find gratification, however, this is not the case. The expectancy-value formula determines the gratifications that will be sought by a media user by summing his or her beliefs about what media can provide weighted by one's evaluations of those beliefs (Foss \& Littlejohn, 2009). Therefore, if a Jua Kali artisan feels that his/her needs will be fulfilled by a particular medium (they believe) he /she will most likely use the media more because of the gratification it gives and because it continuously goes on to meet the expectations of the beliefs they haveOther variables that enter into one's media consumption behavior have been identified. In its most complex form, the theory of uses and gratification also predicts that media-consumption gratifications are influenced by culture, social institutions, media opportunities, circumstances, personal traits, needs, beliefs and values. In turn, one's beliefs about what media can provide are influenced by the gratifications one experiences by using those media (Foss \& Littlejohn, 2009). It could be that television has shown that could benefit Jua Kali artisans however, other factors such as culture, social institutions, media opportunities, circumstances, personal traits, need beliefs and values could be determents in the use of the digital television platform. Therefore, through various adaptations such as the use of recommendation systems, programs can be adopted by engineering Jua Kali artisan needs.

Besides, Digital television is understood as mostly the idea of bringing clear pictures. It was found that respondents thought of the digital television platform as purely using the internet to find information in the form of illustration diagrams and videos, clearly depicting that the digital television platform has mostly been seen to have interesting content mostly from the internet sites only. However, conventional television was found not to show content that is found useful to the Jua Kali artisan or interesting to the Jua Kali artisans. Television is in transition. Roscoe (2015) cites that the way television is produced and delivered, as well as how and where it is watched, is changing. Television can no longer be understood as an autonomous medium, but rather as being connected to other screens (Internet, mobile phone) and cultural sites (sports fields, theme parks, sets). It is as much embedded in public spheres as in domestic ones and as a consequence the ways in which we engage with television have also changed. Additionally, this attitude can be sensitized on the Jua Kali engineering artisans who again can be made to understand TV not only exists at home but also on all forms of mobile gadgets. It could be a useful tool of learning and reference, especially in creating innovations.

Media producers can also be sensitized to understand, television programs are no longer produced (or engaged with) in isolation from other media texts, and new viewing practices are emerging. This transition space is marked by the contradictory forces of convergence, divergence, and dispersal. If we examine production processes, content, and patterns of viewing we can see these discourses in simultaneous operation. On the one hand, we have a convergence of previously discreet and distinct media forms and processes (Lister, et.al, 2003). Drawn together and combined through digital technologies, such convergence occurs at the level of production, distribution, and in terms of the content styles and modes (Kilborn, 2003; Roscoe \& Hight, 2001). At the same time there is convergence in terms of media ownership and a shift toward larger global conglomerates. There is also a greater sense of divergence, with content now delivered in distinct and unique ways to media sites such as the mobile phone and the Internet. There is a proliferation of material generated within media loops of print, broadcast, and telecommunications. Technological convergence has resulted in content and audience divergence. Content is more dispersed across these platforms, and our engagement with it is more fleeting (Roscoe 2015). With this in mind, various efforts can be undertaken, including that of being unconventional in 
diverging content, not just through the traditional mediums, but also by different forms of convergence which can be applied just to make this concept acceptable.

Our experience of contemporary media is more fragmented rather than unified or centralized. Instead of our viewing habits being controlled through the "flow" of schedules (Williams, 1974), our viewing is now clustered around events, and through technologies such as personal video recorders, DVDs, and subscription television services. Choice is the buzzword for both broadcasters and audiences.

Multi-platform event television sets, up a relationship between producers and audiences that is based on a number of assumptions. Audiences are assumed to be both technologically savvy and knowledgeable about the processes of mediation. So audiences are assumed to understand and use the Internet, e-mail and mobile phone technologies. They are also assumed to be familiar with traditional televisual codes, and understand how certain formats re-mediate such conventions (Bolter \& Grusin, 1999). They are in and on the game, and are willing to play. Producers also assume that at least a portion of the audience will engage with the content across these different platforms and understand the relationship between the different forms and styles of delivery. Importantly, this relationship also assumes "playfulness" on behalf of both audiences and producers (Roscoe 2015). This argument by Roscoe compared with the finding that media producers already have knowledge about the possibility of having captivating content is coinciding. We then must not limit Jua Kali artisans because we assume they cannot access content for any reason, rather media producers must continuously apply themselves to make content more and more available to these needful Jua Kali artisans.

From the literature reviewed on the ways content shown in the digital platform inspires creativity, some insights have been gained in the use of digital platforms in particular areas of Africa and the efforts already in place to enhance the use of media in gaining knowledge. There is no doubt that information and communication technologies have influenced educational circumstances more than any other category (Asnafi, 2008). Therefore Jua Kali artisans can consider digital television as a tool of work and a tool for learning.

\section{CONCLUSION}

Communication technology is changing so rapidly that many people speak of a communication revolution. This research has focused on the technological gaps in the Kenyan industry that might hinder the use of digital evison in giving innovation information. This research has focused on attitudinal issues as well. It is likely that Kenyan information gap is most likely caused by attitudinal problems as well as inability to access content which are ble in the digital television gadgets that they already have.

\section{REFFERENCES}

[1] Adam, L., Butcher, N., Tusubira, F. F., \& Sibthorpe, C. (2011). Transformation- Ready: The strategy application of information and communication technologies in africa. Education secto study. Africa development bank

[2] Ali, M., Ullah, S., \& Khan, P. (2007). Managing innovation and technology in developing countries . Yonhyun-Don, Seoul, South Korea.

[3] Asnafi A, \& Hamidi A (2008). The role of ICT in developing of knowledge. Center of Iran information and scientific evidence. EJournal; 3(2). Available at: http://aeizhazmi.persianblog.ir/post/13

[4] Bell, A. (2005) "“An Endangered Species": Local Programming in the New Zealand Television Market', Media Culture \& Society 17(2): 181-200.

[5] Berman, R. (1987). How television sees its audience: A look at the looking glass. Newbury Park, CA: Sage Publications.

[6] Bolter, D. \& Grusin, R.(1999) Remediation: Understanding New Media Revised ed. Edition. Boston Massachusettes. The MIT Press

[7] Creswell, J., \& Plano Clark, V. (2007). Designing and Conducting Mixed Methods Research. Thousand Oaks, CA: Sage

[8] Creswell, J. (2009). Research design: Qualitative, quantitative and mixed methods approach. Carlifornia: Sage publications.

[9] Dyer, E. C. (2010). Reality television: Using para-social relationship theory and economic theory to define the success of network reality programming. (Master's thesis, university of North Texas, Texas).

[10] Foss, K. A. \& Littlejohn, W. S. (2009).Encyclopedia of communication theory. Carlifornia. Sage publications Ltd.

[11] Gay, L. R., Mills, G. E., \& Airasian, P. W. (2009). Educational research: Competencies for analysis and applications (9th edition). Upper Saddle River, New Jersey: Prentice Hall.

[12] Hirschorn, M. (2007,).The case for reality TV. The Atlantic Retrievedfromhttp://www.theatlantic.com/magazine/archive/2007/05/the-case-for-realitytv/5791 The Atlantic Johnson, R.B. and Onwuegbuzie, A.J. (2004) "Mixed methods research: A research paradigm whose time has come", Educational
Researchers, Vol. 33, No. 7, pp 14-26

[14] Johnson, B. \& Christen, L. (2008). Educational Research: Quantitative, Qualitative, and Mixed Approaches. London. SAGE Publications

[15] Kibe, L. (2016). Knowledge sharing techniques amongst Jua Kali artisans in Kenya.Proceedings of the The 11th International Knowledge Management in Organizations Conference on The changing face of Knowledge Management Impacting Society. Article No. 36 . Retrieved from

[16] http://dl.acm.org/citation.cfm?id=2926042\&dl=ACM\&coll=DL\&CFID=823839798\&CFTOKEN=50012859

[17] King, K. (1996). Jua Kali Kenya: Change \& development in an informal economy. Nairobi. East African Publishers.

[18] kilbourne J. (2003)Can't Buy My Love: How Advertising Changes The Way We Think and Feel. New York, N.Y: Touchstone; 
[19] Kozma, R. (2005). National policies that connect ICT-based education reform to economic and social development. Human Technology, 1(2), 117-156.

[20] Leach, J. (2008). Do new information and communications technologies have a role to play in the achievement of education for all? British Educational Research Journal, 34(6), 783-805.

[21] Lister, M., Dovey, J., Giddings, S., Grant, I., \& Kelly, K. (2009). New Media: A Critical Introduction. London. Routledge.

[22] Medoff, J. N \& Kaye, K. B. (2010). Electronic media: Then now later. (2 $2^{\text {nd }}$ ed.). Burlington. United states. Focal press.

[23] Ndemo, B. (2014, August 18th). Linking Jua Kali innovation for employement and wealth creation.DailyNation.Retrieved fromhttp://www.nation.co.ke/oped/blogs/dot9/ndemo/2274486-2422360-14ulqqwz/index.html

[24] Oliver, B. M. (2014).(Eds). Media and social life. New York. Routledge Publishers.

[25] Patterson, F., Kerrin, M., \& Gatto-Roissard, G. (2009). Characteristics and behaviours of innovative people in organisations. A paper prepared for NESTA Policy and Research Unit (NPRU)

[26] Quail, C. (2012). Television goes online: Myths and realities in the contemporary context. Global Media Journal. 12(20)

[27] Robson, C. (2002). Real world research (2 $2^{\text {nd }}$ ed.). Oxford: Blackwell.

[28] Roscoe, J. (2015). Big Brother Australia Performing the 'real' twenty-four-seven. International Journal of Cultural Studies. vol. 4 no. 4473-488.

[29] Roscoe, J., \& Hight, C. (2001). Faking it: mock-documentary and the subversion of factuality. Manchester: Manchester University Press.

[30] Saunders. M., Philip, L, and Adrian, T. (2007). Research methods for business students (5th ed.). UK Prentice Hall.

[31] Soares, M. \& Viana, p. 2015. Tuning metadata for better movie content-based recommendation systems. Multimedia Tools and Applications. 74,(17), pp 7015-7036

[32] Severin \& Tankard. (2001). Communication theories: Origins, Methods and Uses in the mass media. Texas. Addison Wesley Longman.

[33] Thioune, R.M.C. (2003). Information and communication technologies for development in Africa: Opportunities and challenges for community development. Volume 1. Ottawa: IDRC. Available: http://www.idrc.ca

[34] UNESCO. (2002). Information and Communication Technology in Education - A Curriculum for Schools and Programme for Teacher Development. Paris: UNESCO.

[35] UNCTAD. (2011). World Investment Report. Geneva: United Nations.

[36] UNESCO. (2016). National policy definition in technical and vocational education: Beyond the formal sector. Paper presented at a sub regional seminar for Eastern and Southern African countries. Retrieved from

[37] http://www.unevoc.unesco.org/fileadmin/user_upload/pubs/iug014e.pdf

[38] Van der Ryn, S. and Cowan, S. (2007) Ecological Design, 10th Anniversary, 2nd edn, Island Press, Washington, DC.

[39] Wambaria,W. W (2014). Professional use of electronic communication media in education: a study of secondary schools in machakos county, Kenya. PhD Thesis. Moi University

[40] Wangare, J. B. (2015). Knowledge management in the informal sector. A review of Kenya's Jua Kali industry. International Journal of Economics,Commerce and Management. Vol 3(10) retrieved from http://ijecm.co.uk/wpcontent/uploads/2015/10/31017.pdf

[41] Yin, R.K. 2009). Case study research design and methods. (3rd Ed.). Thousand Oaks, CA: Sage.

[42] Zohrabi. M. (2013).Mixed Method Research: Instruments, Validity, Reliability and Reporting Findings. Theory and Practice in Language Studies. Academy Publishers. Finland Vol. 3, No. 2, pp. 254-262, 